\title{
Validated HPTLC method for simultaneous estimation of metoprolol succinate and ramipril in bulk drug and marketed formulation
}

\author{
Kamini Sethy ${ }^{1}$, Janhavi R Rao ${ }^{2}$, K Raja Rajeswari ${ }^{1 *}$ and KEV Nagoji ${ }^{1}$ \\ ${ }^{1}$ Sri Venkateswara College of Pharmacy, Etcherla-532410, Srikakulum District, Andhra Pradesh, India \\ ${ }^{2}$ Poona College of Pharmacy, Bharati Vidyapeeth Deemed University, Erandwane, Pune-411038, Maharashtra, India
}

\begin{abstract}
This paper describes a new, simple, precise, and accurate HPTLC method for simultaneous estimation of Metoprolol succinate and Ramipril as the bulk drug and in tablet dosage forms. Chromatographic separation of the drugs was performed on aluminum plates precoated with silica gel 60 F254 as the stationary phase and the solvent system consisted of Methanol: Toluene: Ethyl Acetate: Ammonia (2.5:3:5:0.7v/v/v/v). Densitometric evaluation of the separated zones was performed at $209 \mathrm{~nm}$. The two drugs were satisfactorily resolved with $\mathrm{R}_{\mathrm{F}}$ values $\mathbf{0 . 6 7}$, and $\mathbf{0 . 3 7}$ for Metoprolol Succinate and Ramipril, respectively. The accuracy and reliability of the method was assessed by evaluation of linearity (2000-12000 ng/spot for Metoprolol succinate and 200-1200 ng/spot for Ramipril), precision ( intra-day RSD 0.471-1.036\% and inter-day RSD 1.085-1.580\% for Metoprolol Succinate and intra-day RSD 1.057-1.63\% and inter-day RSD 1.024-1.746\% for Ramipril,), accuracy ( $98.95 \pm 0.16 \%$ for Metoprolol and $98.98 \pm 0.41 \%$ for Ramipril), and specificity, in accordance with ICH guidelines.
\end{abstract}

\section{Introduction}

Metoprolol Succinate (Metoprolol) chemically is Bis[(2RS)-1-[4(2-methoxyethyl)phenoxy]-3-[(1- methylethyl)amino]propan-2-ol] butanedioate is a cardio selective beta blocker. Metoprolol is used in the management of hypertension, angina pectoris, cardiac arrhythmias, myocardial infarction and heart failure (Figure 1). Metoprolol is also used in the management of hyperthyroidism and in the prophylactic treatment of migraine.

Ramipril chemically is 4-[2-(1-ethoxycarbonyl-3-phenyl-propyl) aminopropanoyl]-4-azabicycloctane-3-carboxylic acid is a long acting angiotensin converting enzyme (ACE) inhibitor and it is a prodrug, which is hydrolysed after absorption to form the active metabolite ramiprilate which has a long elimination half-life, permitting once daily administration (Figure 2). Ramipril may be effective in indications such as severe essential hypertension and renal hypertension. It has also displayed beneficial effects in patients with moderate to severe congestive heart failure.

Literature survey revealed that HPLC, HPTLC, LC-MS methods for estimation of Metoprolol individually and in combination with other drugs [1-3]. Ramipril has been reported for the estimation as individual or in combination with other drugs in various analytical methods such as HPLC, HPTLC, LC-MS-MS, LCMS, and spectrophotometric methods in bulk drug as well as in<smiles>COCCc1ccc(OCC(O)CNC(C)C)cc1</smiles>

Figure 1. Structure of metoprolol<smiles>CCOC(=O)C1CC2CCCC2N1C(=O)[C@H](C)NC(CCc1ccccc1)C(=O)O</smiles>

Figure 2. Structure of ramipril

plasma, etc [4-15]. Literature has revealed the analytical methods for simultaneous estimation of Metoprolol and Ramipril by RP-HPLC and spectrophotometry [16,17]. However, there is no analytical method reported till date for the simultaneous estimation of Metoprolol Succinate and Ramipril in a combined dosage formulation by HPTLC method. So, this work was taken up for the development and validation by densitometric method which is advantageous over the existing methods interms of sensitivity.

\section{Experimental}

Materials: Working standards of pharmaceutical grade Metoprolol (Batch no. 2148/009) and Ramipril was (Batch no. 16043/01) obtained from Lupin Limited, Pune, India on dried basis as a gift sample. It was used without further purification. Commercial tablets of Metoprolol

${ }^{\star}$ Correspondence to: K Raja Rajeswari, Sri Venkateswara College of Pharmacy, Etcherla-532410, Srikakulum District, Andhra Pradesh, India, Email: kamini.tiki@gmail.com

Key words: thin layer chromatography, densitometry, validation and quantification, metoprolol Succinate, ramipril

Received: April 02, 2019; Accepted: April 24, 2019; Published: April 27, 2019 
and Ramipril in a combined dosage form were purchased from the local market, brand name Starpress R XL-25 (Lupin). All chemicals and reagents (methanol, toluene, ethyl acetate, ammonia) used were of analytical grade and were purchased from Merck Chemicals, India.

Instrumentation: The samples were spotted in the form of bands of width $6 \mathrm{~mm}$ with a Camag 100 microlitre sample (Hamilton, Bonaduz, Switzerland) syringe on precoated silica gel aluminium plate $60 \mathrm{~F}-254,(20 \times 10 \mathrm{~cm})$ with $250 \mu \mathrm{m}$ thickness; E. Merck, Darmstadt, Germany, supplied by Anchrom Technologists, Mumbai) using a Camag Linomat IV applicator (Switzerland). The plates were prewashed by methanol and activated at $110^{\circ} \mathrm{C}$ for $5 \mathrm{~min}$ prior to chromatography. Then the chromatoplate was saturated with ammonia vapours for $30 \mathrm{~min}$. A constant application rate of 0.1 $\mu \mathrm{l} / \mathrm{s}$ was employed and space between two bands was kept at $6 \mathrm{~mm}$. The slit dimension was kept at $5 \times 0.45 \mathrm{~mm}$ and $10 \mathrm{~mm} / \mathrm{s}$ scanning speed was employed. The monochromator bandwidth was set at $20 \mathrm{~nm}$ with $\mathrm{K} 320$ cut off filter, each track was scanned thrice, and baseline correction was used. The mobile phase consisted of methanol: toluene: ethyl acetate: 30\% ammonia (2.5: 3.0: 5.0, $0.7 \mathrm{v} / \mathrm{v} / \mathrm{v} / \mathrm{v}) .11 .2$ $\mathrm{ml}$ of mobile phase was used per chromatography. Linear ascending development was carried out in $20 \times 10 \mathrm{~cm}$ twin trough glass chamber (Camag, Muttenz, Switzerland). Dimensions: length $\times$ width $\times$ height $=$ $12 \times 4.7 \times 12.5 \mathrm{~cm}$. It was saturated (lined on the two bigger sides with filter paper that had been soaked thoroughly with the mobile phase) and the chromatoplate development was carried out in dark with the mobile phase. The optimized chamber saturation time for mobile phase was $30 \mathrm{~min}$ at room temperature $\left(25^{\circ} \mathrm{C} \pm 2\right)$ at relative humidity of 60 $\% \pm 5$. The length of chromatogram run was $8 \mathrm{~cm}$ and approximately 20 min. Subsequent to the development, TLC plates were dried in a current of air with the help of an air dryer in wooden chamber with adequate ventilation. The flow of air in the laboratory was maintained unidirectional (laminar flow, towards exhaust). Densitometric scanning was performed on Camag TLC scanner III in the reflectanceabsorbance mode at $209 \mathrm{~nm}$ for all measurements and operated by CATS software (V4.06, Camag). The source of radiation utilized was deuterium lamp emitting a continuous UV spectrum between 190 and $400 \mathrm{~nm}$. Concentrations of the compound chromatographed were determined from the intensity of diffusely reflected light. Evaluation was via peak areas with linear regression.

Preparation of Standard Stock Solutions: $20 \mathrm{mg}$ of Metoprolol and $2 \mathrm{mg}$ of Ramipril were accurately weighed and transferred to $10 \mathrm{ml}$ volumetric flask. Metoprolol and Ramipril were dissolved in $10 \mathrm{ml}$ of methanol to get Standard solutions of a concentration of $2 \mathrm{mg} / \mathrm{ml}$ of Metoprolol and $0.2 \mathrm{mg} / \mathrm{ml}$ of Ramipril. The standard solution was stored at $2-8^{\circ} \mathrm{C}$, protected from light.

Optimization of the HPTLC method: The TLC procedure was optimized with a view to develop a simultaneous assay method for Metoprolol and Ramipril respectively. Various solvent systems like toluene: ethyl acetate: methanol, chloroform: methanol: ethyl acetate, toluene: ethyl acetate: methanol: ammonia was tried in different concentrations to separate and resolve spots of Metoprolol and Ramiprl from their impurities and other excipients of formulations. Methanol: toluene: ethyl acetate: ammonia (2.5: 3.0: $5.0: 0.7 \mathrm{v} / \mathrm{v} / \mathrm{v} / \mathrm{v}$ ) was found to result in the compact spot and best peak shape of Metoprolol and Ramipril. Metoprolol and Ramipril were satisfactorily resolved with $\mathrm{R}_{\mathrm{f}}$ $0.67 \pm 0.05$ and $0.37 \pm 0.02$ respectively with acceptable resolution and peak shape at wavelength of $209 \mathrm{~nm}$ (Figure 3). In order to reduce the neckless effect TLC chamber was saturated for 20 min using saturation pads. The mobile phase was run upto a distance of $8 \mathrm{~cm}$; which takes

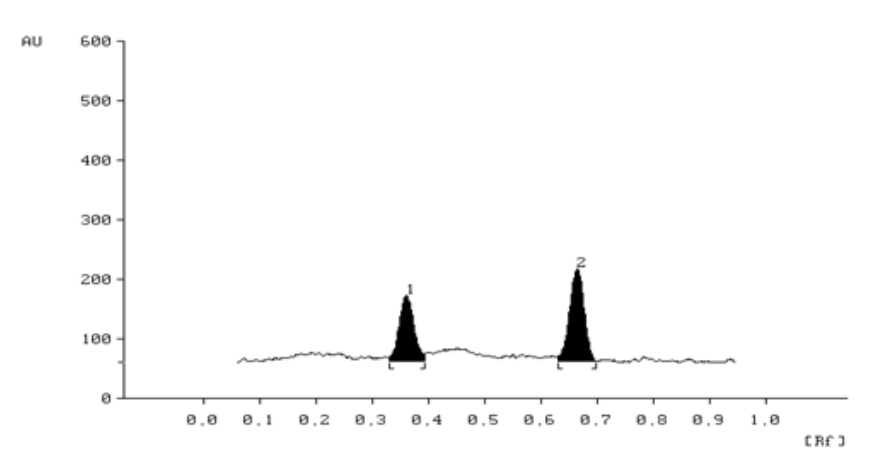

Figure 3. HPTLC densitogram of standard

Peak 1 (200 ng spot-1) of Ramipril (Rf 0.0.37 0.02$)$,

Peak 2 (2000 ng spot-1) of Metoprolol(Rf, $0.67 \pm 0.05$ ).

approximately $20 \mathrm{~min}$ for complete development of the TLC plate.

Validation of the method: Validation of the optimized TLC method was carried out with respect to the following parameters.

Linearity and range: From the mixed standard stock solution 2 $\mathrm{mg} / \mathrm{mL}$ of Metoprolol and $0.2 \mathrm{mg} / \mathrm{mL}$ of Ramipril, 1 to $6 \mu \mathrm{L}$ solution spotted on TLC plate to obtain final concentration 2000-12000 ng/ spot for Metoprolol and200-1200 ng/spot for Ramipril. Linearity of the method was studied by injecting six concentrations of the drug each concentration was applied three times to the TLC plates. The plate was then developed using the previously described mobile phase and the peak areas were plotted against the corresponding concentrations to obtain the calibration curves.

Precision: The precision of the method was verified by repeatability and intermediate precision studies.

Repeatability studies were performed by analysis of three different concentrations (2000,6000, $10000 \mathrm{ng} /$ spot for Metoprolol and 200, $600,1000 \mathrm{ng} / \mathrm{spot}$ for Ramipril) of the drug six times on the same day. The intermediate precision of the method was checked by repeating studies on three different days.

Limit of detection and limit of quantitation: Limit of detection (LOD) and quantification (LOQ) represent the concentration of the analyte that would yield signal-to-noise ratios of 3 for LOD and 10 for LOQ, respectively. LOD and LOQ were determined by measuring the magnitude of analytical background by spotting a blank and calculating the signal-to-noise ratio for Metoprolol and Ramipril by spotting a series of solutions until the $\mathrm{S} / \mathrm{N}$ ratio 3 for LOD and 10 for LOQ. To determine the LOD and LOQ, serial dilutions of mixed standard solution of Metoprolol and Ramipril were made from the standard stock solution in the range of 10-200 ng/spot. The samples were applied to TLC plate and the chromatograms were run and measured signal from the samples was compared with those of blank samples.

Robustness of the method: Following the introduction of small changes in the mobile phase composition $( \pm 0.1 \mathrm{~mL}$ for each component), the effects on the results were examined. Mobile phases having different compositions, e.g. methanol: toluene: ethyl acetate: ammonia (2.6: 3: 5: $0.7 \mathrm{v} / \mathrm{v} / \mathrm{v} / \mathrm{v}),(2.5: 3.1: 5: 0.7 \mathrm{v} / \mathrm{v} / \mathrm{v} / \mathrm{v}),(2.5: 3: 5.1$ : $0.7 \mathrm{v} / \mathrm{v} / \mathrm{v} / \mathrm{v}),(2.5: 3: 5: 0.8 \mathrm{v} / \mathrm{v} / \mathrm{v} / \mathrm{v})$, were tried and chromatograms were run. The amount of mobile phase was varied over the range of $\pm 5 \%$. The plates were prewashed with methanol and activated at $60^{\circ} \mathrm{C}$ for 2,5 , and $7 \mathrm{~min}$ respectively prior to chromatography. The time from spotting to chromatography and from chromatography to scanning was 
varied from $+10 \mathrm{~min}$. The robustness of the method was determined at three different concentration levels $4000,8000,12000 \mathrm{ng} / \mathrm{spot}$ for Metoprolol and 400, 800, $1200 \mathrm{ng} / \mathrm{spot}$ for Ramipril.

Specificity: The specificity of the method was determined by analyzing standard drug and test samples. The spot for Metoprolol and Ramipril in the samples was confirmed by comparing the $R_{F}$ and spectrum of the spot with that of a standard. The peak purity of Metoprolol and Ramipril was determined by comparing the spectrum at three different regions of the spot i.e. peak start (S), peak apex (M) and peak end (E).

Accuracy: Accuracy of the method was carried out by applying the method to drug sample (Metoprolol and Ramipril combination tablet) to which know amount of Metoprolol and Ramipril standard powder corresponding to 80,100 and $120 \%$ of label claim had been added (standard addition), mixed and the powder was extracted and analyzed by running chromatogram in optimized mobile phase.

Analysis of a marketed formulation: To determine the content of Metoprolol and Ramipril in conventional tablet (Brand name: Starpress R XL25 Label claim: $25 \mathrm{mg}$ Metoprolol and $2.5 \mathrm{mg}$ Ramipril per tablet), ten tablets were weighed, their mean weight determined and finely powdered. The weight of the tablet triturate equivalent to $25 \mathrm{mg}$ Metoprolol and $2.5 \mathrm{mg}$ Ramipril was transferred into a 25 $\mathrm{mL}$ volumetric flask containing 10-15 mL methanol, sonicated for $30 \mathrm{~min}$ and diluted to $25 \mathrm{~mL}$ with methanol. The resulting solution was centrifuged at $3000 \mathrm{rpm}$ for $5 \mathrm{~min}$ and the drug content of the supernatant was determined ( 1000 and $100 \mu \mathrm{g} / \mathrm{mL}$ for Metoprolol and Ramipril respectively). $2 \mu \mathrm{L}$ of this solution (2000 and $200 \mathrm{ng} / \mathrm{spot}$ for Metoprolol and Ramipril respectively) was applied to a TLC plate which was developed in optimized mobile phase. The analysis was repeated in triplicate. The possibility of excipient interference with the analysis was examined.

\section{Results and discussion}

The results of validation studies on simultaneous estimation method developed for Metoprolol and Ramipril in the current study involving Methanol: toluene: ethyl acetate: ammonia (2.5: 3.0: 5.0: 0.7 $\mathrm{v} / \mathrm{v} / \mathrm{v} / \mathrm{v}$ ) as the mobile phase for TLC are given below.

Linearity: The drug response was linear $\left(\mathrm{r}^{2}=0.997\right.$ for Metoprolol and 0.999 for Ramipril) over the concentration range between 2000$12000 \mathrm{ng} / \mathrm{spot}$ for Metoprolol and 200-1200 ng/spot for Ramipril. The slope and intercept for Metoprolol and Ramipril were $1.284( \pm 0.982)$, $1979( \pm 1.25)$ and $2.947( \pm 0.862)$ and $658( \pm 1.06)$, respectively.

Precision: The results of the repeatability and intermediate precision experiments are shown in (Table 1). The developed method was found to be precise as the RSD values for repeatability and intermediate precision studies were $<2 \%$, respectively as recommended by $\mathrm{ICH}$ guidelines.

LOD and LOQ: Signal-to-noise ratios of 3: 1 and 10: 1 were obtained for the LOD and LOQ respectively. The LOD and LOQ were found to be $50 \mathrm{ng} / \mathrm{spot}$ and $100 \mathrm{ng} / \mathrm{spot}$ for Metoprolol and $50 \mathrm{ng} / \mathrm{spot}$ and $150 \mathrm{ng} / \mathrm{spot}$ for Ramipril, respectively.

The standard deviation of peak areas was calculated for each parameter and the $\%$ RSD was found to be less than $2 \%$. The low values of the \% RSD, as shown in indicated robustness of the method (Table 2).

Specificity: The peak purity of Metoprolol and Ramipril was assessed by comparing their respective spectra at the peak start, apex, and peak end positions of the spot,i.e., $r(S, M)=0.998$ and $r(M$, $\mathrm{E})=0.999$. A good correlation $(\mathrm{r}=0.9997)$ was also obtained between the standard and sample spectra of Metoprolol and Ramipril, respectively. Also, excipients from formulation were not interfering with the assay.

Recovery Studies: As shown from the data in good recoveries of the Thiocolchicoside and Aceclofenac in the range from 98.32 to 99.45 $\%$ were obtained at various added concentrations (Table 3 ). The average recovery of three levels (nine determinations) for Metoprolol and Ramipril were $98.95 \%$ and $98.98 \%$ respectively.

Analysis of a formulation: Experimental results of the amount of Metoprolol and Ramipril in tablets, expressed as a percentage of label claim were in good agreement with the label claims thereby suggesting that there is no interference from any of the excipients, which are normally present in tablets. The average drug content was found to be $99.52 \%$ and $99.6 \%$ for Metoprolol and Ramipril, respectively, using the proposed procedures and the results are summarized in (Table 4).

\section{Conclusion}

The developed TLC technique is precise, specific and accurate. Statistical analysis proves that the method is suitable for the analysis of Metoprolol and Ramipril as bulk drug and in pharmaceutical formulation without any interference from the excipients. It may be extended to study the degradation kinetics of Metoprolol and Ramipril and also for its estimation in plasma and other biological fluids. The

Table 1. Precision study for metoprolol and ramipril

\begin{tabular}{|c|c|c|c|c|c|}
\hline \multirow{2}{*}{ Drug } & \multirow{2}{*}{$\begin{array}{c}\text { Concentration } \\
\text { ng per band }\end{array}$} & \multicolumn{2}{|c|}{ Intra-day (n=3) } & \multicolumn{2}{|c|}{ Inter-day (n=3) } \\
\cline { 2 - 6 } & 60 & 14.28 & 1.040 & 18.15 & 1.326 \\
\hline \multirow{3}{*}{ Metoprolol } & 120 & 6.96 & 0.317 & 5.91 & 0.269 \\
\cline { 2 - 6 } & 180 & 24.83 & 0.865 & 32.73 & 1.141 \\
\cline { 2 - 6 } & 60 & 56.65 & 1.904 & 49.86 & 1.708 \\
\hline \multirow{3}{*}{ Ramipril } & 120 & 33.97 & 0.671 & 31.33 & 0.618 \\
\cline { 2 - 6 } & 180 & 40.51 & 0.627 & 41.03 & 0.635 \\
\hline
\end{tabular}

Table 2. Robustness testing of metoprol and ramipril

\begin{tabular}{|c|c|c|c|c|}
\hline \multirow{2}{*}{ Parameters } & \multicolumn{2}{|c|}{ Metoprolol } & \multicolumn{2}{|c|}{ Ramipril } \\
\hline & SD & $\%$ RSD* & SD & \%RSD* \\
\hline Mobile phase composition $( \pm 0.1 \mathrm{ml})$ & 10.42 & 1.235 & 10.42 & 1.235 \\
\hline Amount of mobile phase $( \pm 0.5 \%)$ & 20.14 & 1.018 & 20.14 & 1.018 \\
\hline Time from spotting to chromatography $( \pm 20 \mathrm{~min})$ & 15.36 & 0.942 & 15.36 & 0.942 \\
\hline Time from chromatography to scanning ( $\pm 20 \mathrm{~min}$ ) & 20.10 & 1.085 & 20.10 & 1.085 \\
\hline
\end{tabular}

Table 3. Recovery studies of metoprolol and ramipril

\begin{tabular}{|c|c|c|c|c|}
\hline $\begin{array}{c}\text { Label claim } \\
\text { (mg/tablet) }\end{array}$ & $\begin{array}{c}\text { Amount } \\
\text { Added } \\
\text { (\%) }\end{array}$ & $\begin{array}{c}\text { Total } \\
\text { amount } \\
\text { (mg) }\end{array}$ & $\begin{array}{c}\text { Amount* } \\
\text { recovered } \\
\text { (mg } \mathbf{\%} \text { \% RSD) }\end{array}$ & $\begin{array}{c}\text { Recovery } \\
\text { (\%) }\end{array}$ \\
\hline \multirow{2}{*}{$\begin{array}{c}\text { Metoprolol } \\
25\end{array}$} & $80(20 \mathrm{mg})$ & 45 & $44.65 \pm 0.222$ & 99.22 \\
\cline { 2 - 5 } & $100(25 \mathrm{mg})$ & 50 & $49.16 \pm 0.154$ & 98.32 \\
\cline { 2 - 5 } & $120(30 \mathrm{mg})$ & 55 & $54.63 \pm 0.130$ & 99.32 \\
\hline \multirow{2}{*}{$\begin{array}{c}\text { Ramipril } \\
2.5\end{array}$} & $80(2 \mathrm{mg})$ & 4.5 & $4.46 \pm 0.526$ & 99.11 \\
\cline { 2 - 5 } & $100(2.5 \mathrm{mg})$ & 5.0 & $4.92 \pm 0.360$ & 98.4 \\
\hline \multirow{2}{*}{$=3$} & $120(3 \mathrm{mg})$ & 5.5 & $5.47 \pm 0.344$ & 99.45 \\
\hline
\end{tabular}

Table 4. Results from assay of Metoprolol, Ramipril in Starpress R XL 25 tablet

\begin{tabular}{|c|c|c|c|}
\hline Component & $\begin{array}{c}\text { Label } \\
\text { claim(mg) }\end{array}$ & $\begin{array}{c}\text { Amount found } \\
\mathbf{M g} \pm \mathbf{S D}, \mathbf{n}=\mathbf{6}\end{array}$ & $\begin{array}{c}\text { Percentage of label } \\
\text { claim }( \pm \mathbf{S D})\end{array}$ \\
\hline Metoprolol & 25 & $24.88 \pm 35.84$ & $99.52 \% \pm 15.15$ \\
\hline Ramipril & 2.5 & $2.49 \pm 18.87$ & $99.6 \% \pm 10.21$ \\
\hline
\end{tabular}


proposed TLC method is less expensive, simpler, rapid, and more flexible than HPLC.

\section{Acknowledgement}

The authors would like to thank, Lupin Limited, Pune, India for providing gift samples of standard Metoprolol Tartarate and Ramipril. The authors would like to thank, Dr. K. R. Mahadik, Principal, Poona College of Pharmacy, Pune, India for providing necessary facilities to carry out the work.

\section{References}

1. Mitesh D Phale, Purnima D Hamrapurkar (2009) A validated and simplified RP-HPLC of Metoprolol succinate from bulk drugs. Asian J. Research Chem.

2. Rajendra Kakde, Nilesh Bawane (2009) High-performance thin-layer chromatographic method for simultaneous analysis of metoprolol succinate and amlodipine besylate in pharmaceutical preparations. Journal of Planar Chromatography 22: 115-119.

3. P. Senthamil Selvan, TK Pal (2009) Chromatography-tandem mass spectrometry method for the simultaneous quantitation of metoprolol succinate and simvastatin in human plasma. 49: 780-785. [Crossref]

4. F Belal, IA Al-Zaagi, EA Gadkariem, MA Abounassif (2001) A stability-indicating LC method for the simultaneous determination of ramipril and hydrochlorothiazide in dosage forms. Journal of Pharmaceutical and Biomedical Analysis 24: 335-342. [Crossref]

5. K. Srinivasa Rao, K. Srinivas (2010) RP-HPLC method for the determination of Losartan Potassium and Ramipril in combined dosage form. Indian J. Pharm. Sci 72: 108-111. [Crossref]

6. Lincy Joseph, Mathew George, Venkata Ranga Rao B (2018) Simultaneous estimation of Atorvastatin and Ramipril by RP-HPLC and spectroscopy. Pak. J. Pharm. Sci 21: 282-284. [Crossref]

7. Hiral J. Panchal, Bhanubhai N. Suhagia, Natvarlal J. Patel, Ishwarsinh S. Rathod, Bhavesh H.Patel (2009) Simultaneous estimation of Atorvastatin Calcium, Ramipril and Aspirin in capsule dosage form by RP-HPLC, Chromatographia.
8. V P Kurade, MG Pai, R Gude (2009) RP-HPLC estimation of Ramipril and Telmisartan in tablets, Indian Journal of Pharmaceutical Sciences 71: 148-151. [Crossref]

9. MM Baing, VV Vaidya, RT Sane, SN Menon, K Dalvi (2006) Simultaneous RPHPLC determination of Losartan Potassium, Ramipril, and Hydrochlorothiazide in pharmaceutical preparations, Chromatographia, 64, September (No. 5/6)

10. Hiral J. Panchal, Bhanubhai N. Suhagia, Natvarlal J. Patel (2009) Simultaneous HPTLC analysis of Atorvastatin Calcium, Ramipril and Aspirin in a capsule dosage form. Journal of Planar Chromatography 22: 4.

11. Bo Yuan, Xuan Wang, Fenge Zhang, Jun Jia, Fangling Tang (2008) Simultaneous Determination of Ramipril and its active metabolite Ramiprilat in human plasma by LC-MS-MS. Chromatographia 68: 533-539.

12. K. Veeran Gowda, Uttam Mandal, P. Senthamil Selvan, W.D. Sam Solomon, Animesh Ghosh, (2007) Liquid chromatography tandem mass spectrometry method for simultaneous determination of metoprolol tartrate and ramipril in human plasma. Journal of Chromatography B 858: 13-21. [Crossref]

13. Bilal YILMAZ Determination of Ramipril in pharmaceutical preparations by highperformance liquid chromatography. International Journal of Pharmaceutical Sciences Review and Research 1: 39.

14. Laxman V. Potale, Mrinalini C. Damle, Amol S. Khodke, K. G. Bothara (2010) A validated stability indicating HPTLC method for simultaneous estimation of Ramipril and Telmisartan. International Journal of Pharmaceutical Sciences Review and Research 2: 7.

15. Priyanka R Patil, Sachin U Rakesh, Pandurang N Dhabale, Kishor B Burade (2009) Simultaneous Estimation of Ramipril and Amlodipine by UV Spectrophotometric Method. Research J. Pharm. and Tech.

16. RJ Chandra Bose, G Sivanseyal, Krishnakumar D (2017) Validated Rp-Hplc Method for the Simultaneous Estimation of Ramipril and Metoprolol Tartrate in Bulk and Tablet Dosage Form. Asian Journal of Biochemical and Pharmaceutical Research 1: 171177.

17. K.Suresh Kumar, R Ravikumar, A Rajasekaran, simultaneous spectrophotometric determination of Metoprolol tartarate and Ramipril. Digest Journal of Nanomaterials and Biostructures 5: 173-176.

Copyright: (C2019 Sethy K. This is an open-access article distributed under the terms of the Creative Commons Attribution License, which permits unrestricted use, distribution, and reproduction in any medium, provided the original author and source are credited. 